\title{
Heidegger, Leitor de Lutero: A Busca por uma Vida Cristã Originária e o Problema do Pecado
}

[Heidegger, Luther's Reader: The Search for a Original Christian Life and the Sin's Problem]

\section{Eric Ewans Mendes»}

Resumo: A influência da Teologia sobre o pensamento inicial de Heidegger é fato comprovado. Na verdade, Heidegger começou sua vida estudantil na Teologia Católica, migrando para a Teologia Protestante, usando-a como auxílio importante no início do seu pensamento filosófico. Vários fatores levaram Heidegger a migrar não somente no campo intelectual como no campo da práxis religiosa, um desses fatores, por exemplo, foi o seu descontentamento com a postura extremamente dogmatista do pensamento Neo-Escolástico. Foi o Reformador Martinho Lutero uma das figuras importantes nessa transição. Por meio dos estudos de seu pensamento, Heidegger procurou responder a algumas questões importantes da problemática teológica. Neste trabalho, além de uma breve exposição da migração de Heidegger do Catolicismo para o Protestantismo, analisaremos como ele trata de duas dessas questões: primeira, acerca da Vida Cristã Originária, e a segunda referindo-se a Lutero e o problema do pecado.

Palavras-chave: Heidegger, Lutero, vida cristã originária, pecado.

Abstract: The influence of theology on Heidegger's initial thinking is a proven fact. In fact, Heidegger began his student life in Catholic Theology, migrating to Protestant theology, using it as an important aid in the beginning of his philosophical thinking. Several factors led Heidegger to migrate not only in the intellectual field but also in the field of religious praxis, one of these factors, for example, was his discontent with the extremely dogmatist stance of Neo-Scholastic thought. The Reformer Martin Luther was one of the important figures in this transition. Through the study of his thought, Heidegger sought to answer some important questions of the theological problematic. In this work, in addition to a brief exposition of Heidegger's migration from Catholicism to Protestantism, we will examine how he deals with two of these questions: first, about the original Christian life, and the second referring to Luther and the problem of sin.

Keywords: Heidegger, Luther, original christian life, sin.

${ }^{*}$ Mestre em Filosofia Social pela Universidade Federal de Mato Grosso (UFMT), e Bacharel em Teologia pela Universidade Presbiteriana Mackenzie. E-mail: ewaristosuper@hotmail.com.

ORCID: https://orcid.org/0000-0001-6049-6464. 


\section{1 - Introdução}

Martin Heidegger, oriundo de uma família católica ultramontanista e antimodernista, iniciou seus estudos na teologia católica em 1911 com o propósito de ser padre. Porém, por problemas de saúde, abandonou o propósito do sacerdócio e, nos anos de 1911 e 1912, após recuperar-se, retorna à faculdade, desistindo da teologia e ingressando nos estudos de filosofia e matemática. Contudo, Heidegger não permaneceu na fé confessionalmente católica, mas migrou para o protestantismo de caráter livre e, durante essa migração, as pesquisas que realizou apontam o quão forte foi sobre ele a influência do pensamento protestante e, principalmente, do jovem Martinho Lutero, acerca da chamada Vida Cristã Originária e do problema do pecado. Assim, este artigo tem por objetivo abordar as seguintes questões: primeiro, uma breve apresentação da migração do jovem Heidegger da religião e do pensamento católicos para o protestantismo; segundo, procurar entender o significado do conceito heideggeriano de "Vida Cristã Originária" e, por último, a leitura que Heidegger faz do entendimento de Lutero sobre o problema do pecado.

\section{2 - A migração do Catolicismo para o Protestantismo livre}

A atenção de Heidegger para as obras protestantes, especialmente as de Martinho Lutero, é de fato um marco na mudança de pensamento na filosofia inicial do jovem filósofo alemão. Ainda que sucintamente, faz-se mister compreender como isso ocorreu.

Pois bem, Heidegger possui suas origens no Catolicismo Romano Ultramontanista e antimodernista. Seu pai havia sido sacristão e sua família chegou a morar em uma casa de propriedade da paróquia em Meßkirch. Segundo Wolfe (2014), a postura de Heidegger, como antimodernista, vinha de seu lar e, também, do ambiente escolar. Por ser o filho mais velho, ele intenta o sacerdócio para padre em sua juventude, indo primeiramente para a escola em Konstanz e, também, para Freiburg nos anos de 1903 a 1909. Em setembro de 1909, Heidegger busca admissão entre os jesuítas, conforme relatado por seu orientador de graduação. Em 6 de setembro do mesmo ano, Heidegger preside a celebração dos 200 anos de aniversário do grande padre orador agostiniano Abraham Sancta Clara (1644-1709).

Wolfe (2014) informa que sua paixão como um apologeta católico também é notada em sua 
contribuição direta na chamada 'guerra entre os jornais', ao escrever um artigo polêmico para o jornal católico Volksblatt (a principal fonte de informação utilizada pelo jovem Heidegger) como para outros periódicos conservadores, especialmente o Der Akademiker e Allgemeine Rundschau, entre os anos de 1909 a 1910. Porém, a mais antiga publicação de Heidegger, de que se tem conhecimento, é uma pequena história lírica que aborda a dramática conversão de um jovem ateu no Dia de Finados, vindo essa publicação a lume em novembro de 1909. Antes dessa publicação, em 30 de setembro do mesmo ano, Heidegger viajou para ingressar nos jesuítas como candidato a noviço, mas foi dispensado devido à descoberta de um problema cardíaco crônico. Entretanto, o jovem Martin, ainda desejoso de tornar-se padre, inicia em Marburg, no inverno de 1909/1910, seus estudos na teologia católica, bruscamente interrompidos em fevereiro de 1911 devido às suas condições cardíacas, forçando-o a retornar a Meßkirch.

No inverno de 1911/1912, Heidegger retoma os estudos, mas não em teologia. Desta vez, ingressa na Faculdade de Filosofia e, em 1912, gradua-se em filosofia e matemática. Em 1913, conclui sua curta dissertação de doutorado em filosofia e, em 1915, termina sua tese de habilitação - Doutrina das Categorias e da Significação em Duns Scott, Wolfe (2014). Tal mudança de postura - de um fervoroso apologeta católico para um protestante livre entre os anos de 1916-1919 - decorreu, em especial, do descontentamento de Heidegger com a postura extremamente dogmática do pensamento Neo-Escolástico, incentivado pelas ordens papais de Pio X de 1914 , bem como pela persistência na "onto-teo-logia" que possui um Deus impessoal e categorizado como a "causa sui". À medida que Heidegger afastavase da teologia escolástica, com o auxílio das leituras filosóficas de Hegel, Schelling, Kierkegaard,

\footnotetext{
${ }^{1}$ Em uma carta para Engelbert Krebs em julho de 1914, Heidegger expressa o seu descontentamento. Ele diz: 'O motu proprio acerca da filosofia era realmente a cereja no bolo. Talvez você como um "acadêmico" poderia aplicar um procedimento até melhor para esvaziar o cérebro de qualquer um que ousar ter um pensamento independente, e substituí-lo por "salada italiana"' (WOLFE, 2014, p. 17; DRAWIN, 2007, p. 2; OTT, 1993, p. 92-93).

${ }^{2}$ MacDowell (2012) afirma que de fato Heidegger teve contato com a teologia protestante estudando profundamente as obras de Lutero tendo a influência de um influxo dessa mesma teologia, porém, a espiritualidade cristã que Heidegger viveu era de cunho estritamente católico. Pöggeler cita a carta de Rudolf Bultmann a Hans von Soden aos 23 de dezembro de 1923: "O seminário é, desta vez, especialmente instrutivo, porque dele participa nosso novo filósofo Heidegger, um discípulo de Husserl. Ele vem do catolicismo, mas é plenamente protestante, o que ele demonstrou recentemente no debate após uma conferência de Hermelink sobre Lutero e a Idade Média. Ele não só possui um destacado conhecimento da escolástica, mas também de Lutero, e deixou Hermelink, de certo modo,
} 
Nietzsche, Dilthey, aproxima-se da teologia protestante (especialmente de Lutero) $)^{2}$, assim se tornando um leitor e estudioso do pensamento teológico de Lutero, Drawin (2007). Demais disso, o seu casamento misto com Elfride Petri, de origem protestante, revela essa mudança religiosa de Heidegger ${ }^{3}$, podendo-se mencionar, outrossim, o seu curriculum vitae, enviado ao filósofo protestante Georg Misch em 1922, onde declara que seu primeiro contato com a teologia protestante foi em 1911. Suas pesquisas sobre a história da religião cristã encontraram harmonia com as dos pensadores protestantes do círculo escolar de Göttingen, no final do século XIX, com destaque para o mais proeminente deles, Albert
Schweitzer. Wolfe (2014).

Esses acontecimentos mostram a passagem de Heidegger de um pensador católico antimodernista para um pensador influenciado pela filosofia e, também, pela teologia protestante, especialmente por Martinho Lutero, que é, para Heidegger, uma das suas referências na busca por uma Vida Cristã Originária. E esta influência de Lutero sobre jovem Heidegger será analisada de maneira mais detida a seguir.

\section{3 - Lutero e a busca por uma Vida Cristã Originária}

\begin{abstract}
A migração de Heidegger do pensamento católico para o pensamento protestante de forma livre (i.e., sem vínculo a uma comu-
\end{abstract}

\footnotetext{
embaraçado; ele realmente compreendera a questão mais a fundo do que aquele. - Foi para mim de interesse, saber que Heidegger também é familiarizado em geral com a moderna teologia e é principalmente um admirador de Hermann - também conhece Gogarten e Barth e aprecia de modo especial o primeiro, de modo semelhante a mim. Podes imaginar como é essencial para mim que você venha para cá e participe deste debate. A geração mais antiga não é incapaz para isso, já que ela já nem entende mais a problemática, pela qual nos empenhamos..." (PÖGGELER, 2000, p. 166). Solari (2005) questiona se porventura, ao abandonar o sistema católico em um cristianismo universal baseado no mundo protestante, teria Heidegger abandonado a fé católica de suas origens. Solari assim como MacDowell menciona as visitas de Heidegger no Convento de Beuron onde ele participava das liturgias, e mencionam ainda mais detalhes sobre isso. John Caputo (2010) informa que Heidegger foi enterrado no cemitério católico de Meßkirch entre as sepulturas de seus pais. Em vida, havia pedido a Bernhard Welte para celebrar um funeral católico na Igreja de São Martinho, onde o seu pai havia servido como sacristão e ele passara parte de sua infância. Wolfe (2014) cita a carta de Husserl para Rudolf Otto informando que nunca influenciou Heidegger ao protestantismo, e também menciona parte da carta de Bultmann a Hans von Soden já citada acima. Van Buren (1994) também informa que a atenção voltada para Lutero por parte de Heidegger após a Primeira Guerra Mundial, possui três fases. E na terceira fase ele envia uma carta a Krebs no dia 09/01/1919, anunciando oficial o seu protestantismo livre. Portanto, o que se pode considerar acerca dessa questão é que ao abandonar o catolicismo e viver como um protestante livre, Heidegger não era impedido de manter aspectos peculiares da sua cultura religiosa de origem, no caso, uma prática litúrgica católica também livre, com a finalidade de nunca esquecer suas raízes, ou melhor, pode-se notar uma espiritualidade de cunho "conciliatório" em Heidegger ao exercer uma espiritualidade protestante livre somada à preservação de práticas da espiritualidade católica que considerava importantes para a busca da Vida Cristã Originária.

${ }^{3}$ Em sua carta a Engelbert Krebs, sacerdote católico e líder espiritual do casal Heidegger, Elfride informa a sua saída e de seu esposo do Catolicismo para um Protestantismo livre, isto é, não preso à "ortodoxia católica ou protestante". Krebs era cético quanto a conversão de Elfride ao catolicismo e de fato estava certo, conforme ela afirma em sua carta, Ott (1993), Wolfe (2014). Nesta última a citação é de apenas uma parte da carta.
} 
nidade eclesiástica) é um marco histórico no seu desenvolvimento filosófico inicial. Destarte, ao distanciar-se da teologia escolástica, ele se aproxima da teologia protestante, especialmente de Lutero ${ }^{4}$, a quem, em sua obra Ontologia (Hermenêutica da Facticidade), ele chama de companheiro de buscas: "O companheiro em minha busca foi o jovem Lutero e o modelo Aristóteles, a quem Lutero odiava." (HEIDEGGER, 2012, p. 11). Para Heidegger, Lutero, com sua teologia, abriu caminho para a busca da chamada Vida Cristã Originária. Duas passagens de duas obras de Heidegger que corroboram este fato podem ser mencionadas:

Em Fenomenologia da Vida Religiosa (1924) $)^{5}$, ele diz:

Entretanto, há nisso um mal-entendido dessa passagem de Paulo [Romanos $1.19 \mathrm{~s}$ - grifo meu]. Lutero foi o primeiro a entendela apropriadamente. Em suas primeiras obras, Lutero abriu uma nova com- preensão do cristianismo originário. Mais tarde, porém, ele mesmo acabou sendo vítima do peso da tradição, começando assim a implantação da escolástica protestante. Os conhecimentos de Lutero da época originária são decisivos para relacionar o cristianismo com a cultura. Isso é algo que hoje passa por despercebido e desconhecido nos esforços pela renovação religiosa e cristã (HEIDEGGER, 2010, p. 270).

Em Fenomenologia da Vida Religiosa, nos anexos de suas palestras sobre "Agostinho e o Neoplatonismo", o filósofo tudesco complementa o comentário sobre questão da Tentatio mencionada por Agostinho no Livro X, capítulo 28, das Confissões. Heidegger afirma que a passagem de Romanos 1.19, tal como descrita por Paulo, é mal compreendida pelos pensadores patrísticos, que a interpretaram como uma ascensão

\footnotetext{
${ }^{4}$ Em uma de suas cartas a Heidegger, Bultmann o informa sobre um artigo que será escrito acerca dele por Wünsch e por isso, pede mais informações além daquelas que ele já conhecia de seu amigo que é a influência de Lutero e outros autores sobre o seu pensamento e também o propósito de suas pesquisas. Heidegger responde pontuado as informações que Bultmann pede: 1. O propósito de seus estudos e 2. Os pensadores que foram fundamentais para a formulação de uma compreensão mais radical do Dasein, Heidegger-Bultmann (2012). Essas duas cartas são muito importantes pelo fato do próprio Heidegger revelar com muita clareza os objetivos de suas pesquisas bem como as influências que recebeu.

${ }^{5}$ Esta obra é resultado das anotações de seus alunos, que participaram em 1921 de suas preleções e de demais colaboradores.
} 
platônica ao divino. Lutero foi o primeiro a compreendê-la corretamente, abrindo portas para a nova compreensão da Vida Cristã Originária, embora, mais tarde, Lutero, como Heidegger assevera, também não tenha escapado das malhas da "Onto-teo-logia", com a implementação da Escolástica Protestante.

Já em Ser e Tempo, pode-se ler:

A Teologia procura por uma interpretação mais originária do ser do homem em relação a Deus, interpretação que seja prescrita pelo sentido da fé ela mesma e que permaneça no seu interior. Lentamente ela começa a entender de novo a visão de Lutero de que sua sistemática dogmática repousa sobre um "fundamento" que não surgiu de um perguntar primário de fé e cuja conceituação não é só insuficiente para a problemática teológica, mas encobre e desfigura (HEIDEGGER, 2012, p. 53, $55)$.
Mas, inicialmente, Lutero é muito importante por seus conhecimentos levarem a compreender o relacionamento do cristianismo com a cultura, o que Heidegger critica passar despercebido pela renovação religiosa e cristã. Lutero é, portanto, a lente de Heidegger para interpretar Agostinho, cuja interpretação também fora platonizante, como se vê na passagem paulina ao "aproximar o Deus da revelação ao ente supremo" (DRAWIN, 2007, p. 4 e 5). Heidegger menciona que a resposta de Lutero contra a interpretação platonizante de Romanos 1.19 são as teses 19,21 e $22^{6}$, as duas últimas sendo desdobramentos da primeira. Em sua obra "Disputatio de Heidelberg", de 1518, Lutero "repõe o intelecto em sua posição de efetiva impotência e reafirma a miséria da condição humana" (DRAWIN, 2007, p. 7).

Por cair nas malhas do pensamento "onto-teo-lógico", a sistemática dogmática impede que se tenha uma visão originária da fé que leve a uma Vida Cristã Originária e à importante relação do Cristianismo com a cultura. A influência de Lutero em seu pensa-

\footnotetext{
${ }^{6}$ Heidegger e comenta essas teses de Lutero: Tese 19 - "Não merece o nome teólogo aquele que vislumbra o invisível de Deus através daquilo que tiver sido criado" - A apresentação [Vorgaube] da teologia não deve ser procurada e conquistada pela via de uma consideração metafísica de mundo. Tese 21 - "Para o Theologus gloriae [Teólogo da glória], que se compraz esteticamente com as maravilhas do mundo, nomeando o sensível que há em Deus." - O teólogo da cruz diz como as coisas são. Tese 22 - "Vossa sabedoria, que vislumbra o invisível de Deus nas obras, inflama, cega e endurece" (HEIDEGGER, 2010, p.270; LUTERO, 1987, p.39). A tese 22 demonstra ser autoexplicativa.
} 
mento levaria o jovem Heidegger a remeter-se à sua própria experiência religiosa, uma religiosidade vivida e exemplarmente encarnada na figura de seu pai, Friedrich Heidegger, e do Padre Abraham Sancta Clara, homenageado por Heidegger em um escrito no ano de 1910. Drawin explicita o que se entende por experiência cristã originária:

[...] a vida autêntica, mesmo para um homem de alta cultura intelectual, como o Padre Abraham, passa pela experiência da radical contigência do humano, pelo reconhecimento da condição frágil e indigente, simultaneamente carnal e temporal, do ser humano e que encontrou a sua expressão paradigmática em Jesus Crucificado. É inevitável o remetimento à teologia paulina: $\mathrm{O}$ Hino a Cristo servo sofredor na "Epístola aos Filipenses" (2,6-11), que proclama o Deus que "esvazia-se de si mesmo" (heuaton ekenôsen), despojando-se na

\begin{abstract}
humilde condição da existência humana (DRAWIN, 2007, p. 3).
\end{abstract}

Essa é a experiência Cristã Originária, na qual se relaciona não com o Deus impessoal da metafísica ou onto-teo-logia, mas com o Deus vivo e pessoal da revelação, que se faz conhecer através da vida de Jesus Cristo7, que, na radical contingência da experiência humana, frágil (angústia e medo), indigente, carnal e temporal (a possibilidade da morte), é seu modelo na condição da existência humana que se resume em Dom e Tarefa - Gabe und Aufgabe - onde a razão necessita acolher a gratuidade da experiência humana e colocar-se a seu serviço, por não poder instaurar nada por si mesma, Drawin (2007). Em termos práticos, o cristão, seja católico ou protestante, ao aproximarse por meio de Jesus Cristo, durante a liturgia de culto, não faz uso de argumentações ou postulações teológicas sobre a pessoa de Deus, mas simplesmente crê e é consciente da necessidade de espelhar-se na pessoa de Cristo, reconhecendo sua temporalidade, sua fragilidade e a necessidade de

\footnotetext{
${ }^{7}$ A theologia crucis de Paulo interpretada por Lutero vista nas teses 19, 21, 22 de sua Disputatio foi muito importante nessa busca heideggeriana pela experiência cristã originária. Drawin cita Lutero: "Pois, como ensina Lutero: no Cristo crucificado é que estão a verdadeira teologia e o verdadeiro conhecimento de Deus" (LUTERO, 2004, p. 50, Apud DRAWIN, 2007, p.7). Buren (1994).
} 
obediência aos mandamentos de Deus no seu dia-a-dia.

Essa Vida Cristã Originária segundo Gadamer (2012), cumpria os propósitos do que Heidegger buscava em seu projeto filosófico cuja motivação era libertar-se das influências da teologia ${ }^{8}$ na qual tinha sido educado para ser cristão, sendo que sua preocupação, na busca da Vida Cristã Originária, tendo Lutero como uma das importantes influências, leva-o também a outra inquietação em relação a essa experiência cristã: o problema do pecado. A pergunta é: como Lutero lidou com esse problema?

\section{4 - Lutero e o problema do pecado}

$\mathrm{Na}$ tentativa de responder a esta pergunta, é necessário considerar algumas informações preliminares: 1. Heidegger desenvolveu seu entendimento da relação entre pecado, morte e filosofia graças ao seu compromisso com o estudo de Lutero. Karl Jaspers testemunhou, durante sua visita a Freiburg, na primavera de 1920, a intensidade com que Heidegger dedica-se ao estudo. 2. Heidegger, em carta a sua esposa, no final de 1920, declara que Lutero é indispensável para seu trabalho. 3. Os trabalhos, em conjunto com o renomado Teólogo Protestante, Rudolf Bultmann, em Marburg, como 'O problema do pecado em Lutero', em 1924, e 'Sobre o comentário de Lutero nas cartas de Paulo aos Gálatas em 1927', Wolfe (2014), Buren (1994).

Também é importante lembrar que em sua pesquisa sobre "O problema do pecado em Lutero" e a busca de compreensão do cristianismo originário, Heidegger faz observações críticas a Max Scheler em seu livro Ontologia: Hermenêutica da Facticidade. Essas críticas referem-se à definição de homem de Scheler como "intenção e gestão da 'transcendência' mesma" ou "aquele que busca a Deus" (HEIDEGGER, 2012, p. 35). Heidegger afirma que tais afirmações de Scheler assemelham-se ao "ter respeito com..." de Kant e mostram-se uma confusão. Eis a afirmação de Heidegger:

O alcance do grau de confusão que ocorre nessas abordagens fundamentais de Scheler é indicada, entre outras coisas, pelo fato

\footnotetext{
${ }^{8}$ Heidegger considera que para conseguir tal finalidade filosófica é necessário que a investigação seja a-teológica ou a-téia, isso implica distanciar-se filosoficamente do Deus da metafísica e da desvinculação consciente em relação a qualquer matriz religiosa (que impeça que seu objeto e ponto de chegada de sua indagação sejam ditados) para tentar a difícil tarefa de aproximar-se do Deus divino. Heidegger (2006), (GA 61), Fabris (2006), Drawin (2007).
} 
de sua idéia de pessoa coincidir justamente, até mesmo literalmente, com a formulação que os reformadores, em oposição ao Aristóteles trivializado pela escolástica, proporcionaram; cf. Zwinglio, Calvino. E, além disso, esquece-se precisamente neste contexto, isto é, no contexto teológico, que é preciso distinguir fundamentalmente vários estados ou modos do ser do homem (status integritatis [estado de integridade], status corruptionis [estado de corrupção], status gratiae [estado de graça], status gloriae [estado de glória]) que não podem ser trocados arbitrariamente uns pelos outros. Quando Scheler diz: "Lutero foi o primeiro a defini-lo [a definir o homem] explicitamente como 'caro' (carne)", deve-se observar que Scheler confunde aqui Lutero com o profeta Isaías $(40,6)$. Cf. Lutero: Porro caro significant totum hominem cum rati- one et omnibus naturalibus donis [Carne aqui significa o homem todo, com a razão e todos os dotes naturais]. Este em status corruptionis, o qual, no entanto, está totalmente determinado de saída. A ele pertencem o ignorantia Dei [ignorância de Deus], securitas [segurança], incredulitas [descrença], odium erga Deum [raiva de Deus]. Trata-se de uma relação negativamente determinada contra Deus, de um confronto com Deus. Isso enquanto tal é constitutivo! (HEIDEGGER, 2012, p. 35,36$)$.

O erro de Scheler, como acusa Heidegger, é a sua má compreensão do que é o entendimento de Lutero sobre o Status Corruptionis. E essa questão é o principal foco de Heidegger, que intenta trazer a lume não somente o seu entendimento do Status Corruptionis, mas apresentar como o reformador alemão lidou com esse problema. Heidegger afirma: "O objeto da teologia é Deus. O tema da teologia é como o homem é em seu ser

\footnotetext{
${ }^{9}$ Tradução nossa: The object of theology is God. The theme of theology is man in the how of his being-placed before God.

${ }^{10}$ Esta obra de título: Supplements: From the Earliest Essays to Being and Time and Beyond, são ensaios das
} 
colocado diante de Deus" ${ }^{9}$ (HEIDEGGER, 2002 [1924], p. 105) Heidegger questiona: quando o pecado passa a ser discutido como um problema teológico? É a partir da fundamental tendência de Lutero, que o jovem Martin define:

A fundamental tendência em Lutero é encontrada desta maneira: a Corruptio [Corrupção] do ser do homem nunca pode ser apreendida [grasped] radicalmente o suficiente e ele disse isso precisamente em oposição ao Escolasticismo, que ao falar de Corruptio sempre minimizava (HEIDEGGER, 2002, p. 106)

Essa afirmação de Heidegger apresenta a diferença de como o pensamento escolástico e Lutero viam e tratavam a corruptio. Enquanto Lutero a considera como um grande problema a se lidar, o Escolasticismo, por sua vez, a minimiza como algo de pouca importância. Para trabalhar isso, dois pontos serão apresentados por Heidegger: primeiro, a ten- dência antes do problema no primeiro período do pensamento de Lutero, e; segundo, o que Lutero, em seu segundo período de pensamento (Lutero tardio), trata sobre essa tendência.

$\mathrm{Na}$ "Quaestio de viribus [et voluntare hominis sine gratia]" [A Questão da Capacidade do Homem e Vontade sem a Graça] do ano de 1516, Heidegger afirma que Lutero via o pecado como desvio de atenção para o afeto, no qual o homem que é ser-lançado passa ao ser-horrorizado [Entsetztsein] e este sentimento de horror é, segundo Lutero, baseado na busca pela retidão. Esta busca é um desespero diante de Deus por causa dos affectus hordens peccatum (afeto de ser aterrorizado pelo pecado). A ênfase de Lutero está no affectus subtilissime carnalis (mais simples afeto da carne) uma posição contrária ao Escolasticismo que defende: corruptio amplificada est (corrupção é algo a ser amplificada), Heidegger (2002). Por isso a acusação de Heidegger aos escolásticos na minimização da Corruptio.

Heidegger apresenta essa diferença defendida por Lutero na "Disputatio contra scholasticam

palestras de Heidegger, traduzidas do alemão para o inglês sob a organização de John Van Buren. A parte a ser consultada dela é a palestra de Heidegger de 1924 na apresentação do problema do pecado em Lutero. Essa palestra é dividida em duas partes. Heidegger (2002).

${ }^{11}$ Tradução nossa: The fundamental tendency in Luther is found in this manner: the Corruptio [corruption] of being of man can never be grasped radically enough - and he said this precisely in opposition to Scholasticism, which in speaking of corruptio always minimized it. 
theologian" [Debate contra a Teologia Escolástica] de 1517, com a citação das teses $17,25,30,37$. Nessas teses, Lutero declara:

Por natureza, o ser humano não consegue querer que Deus seja Deus; pelo contrário, quer que ele mesmo seja Deus e que Deus não seja Deus. A esperança não vem de méritos, mas de sofrimentos que destroem méritos. Contra a prática de muitos. Da parte do ser humano, entretanto, nada precede à graça senão indisposição e até mesmo rebelião contra a graça. A natureza até necessariamente se vangloria e orgulha por dentro da obra que, na aparência e exteriormente, é boa (LUTERO, 1987 , p. 16, 17).

Heidegger (2002) faz algumas observações importantes: A primeira é que, na tese 17, Lutero aponta qual é precisamente a natureza do pecado: o desejo do homem de ser Deus e de retirar Deus de sua posição como divino. Em segundo lugar, Heidegger não explica a tese 25, deixa-a como autoexplicativa, significando que o sofrimento é o meio pelo qual a esperança pode manifestar-se. Como terceira observação, a possibilidade de a graça não poder ser criada no homem devido ao seu estado de rebelião contra a própria graça, como explica a tese 30. Por último, Heidegger observa a afirmação de Lutero de que toda a ação humana é ao mesmo tempo presunçosa e pecaminosa, o que distingue sua posição daquela de Aristóteles e de toda ontologia grega, como o próprio Lutero afirma na tese 50, usando a ilustração da diferença entre a luz e a escuridão para afirmar a diferença entre o todo da filosofia aristotélica e da teologia.

Mais uma diferença apontada por Lutero segundo Heidegger (2002), é entre os dois pontos de vista teológicos: a (theologia gloriae), ou "teologia da glória" (teses 21 e 22) da (theologia crucis) "teologia da cruz". A primeira apresenta a visão das coisas invisíveis de Deus nas obras como percebidas pelo homem. A segunda, oposta à primeira, considera unicamente os pontos de partida da atual questão. Heidegger afirma que o Escolasticismo, em seu ponto de vista grego, faz o homem ficar orgulhoso, pois tem uma concepção de Cristo meramente subsequente após a definição de Deus e do mundo. O que se deve fazer é, em primeiro lugar, ir à cruz antes de dizer que 
a questão atual é, por exemplo, sobre Deus e o mundo. Para Philippe Capelle (2012), Heidegger, em seu projeto da vida fática da experiência cristã primitiva, reivindica, com base em Lutero, a teologia da cruz contra a escolástica teologia da glória, pois o jovem Lutero renova a teologia com base soteriológica.

A questão do problema do pecado e iustitia originalis em Lutero é, também, um exame desses problemas no Escolasticismo. A questão da iustitia originalis, conforme Heidegger (2002), é dependente da visão básica de que a Igreja é a autoridade em matéria de fé, de tal modo que, ainda que se considere a Igreja como uma instituição divina, necessita-se apresentar duas questões racionais importantes: a primeira é a prova da existência de Deus; a segunda é a possibilidade de uma Revelação histórica. Esses pontos só podem ser levados em consideração se a natura hominis [natureza do homem] é integra [intocada], mesmo após a Queda.

É aqui que Heidegger aponta a diferença entre o pensamento escolástico e o luterano. Para os escolásticos, a natureza humana continua após a Queda intocada, isto é, ela não foi obliterada com a Queda. Lutero, por sua vez, apelando para a experiência, em seu entendimento do status corrupti- onis, afirma que o homem como imagem e semelhança de Deus teve, sim, sua natureza obliterada com a Queda, Wolfe (2014). Na Queda, a natura hominis é corrupta [corrupta], por causa do pecado. Heidegger discorre:

O ser do homem como tal é em si mesmo pecado. Pecado é nada mais que a antítese da fé, onde fé significa: de pé (ser colocado) diante de Deus. Assim, pecado não é uma afixação dos atributos morais ao homem, mas bem seu núcleo original. Em Lutero, pecado é um conceito de existência, algo para o qual sua ênfase em affectus já aponta. Além dessa definição fundamental do homem, Lutero volta sua atenção para o movimento do pecado como um modo do homem suportar à si mesmo: Um pecado gera outro e arrasta o homem ainda mais para o fundo. A origem do pecado é incredulitas, i.é., incredulidade, aversio dei [distanciamento de Deus]. O que é incluído nisso, enquanto como homem é em seu ser-distanciado-de Deus lançado dentro do mundo, 
é um pavor [medo]. E com isso em mais sucessões: fuga [fuga], odium [ódio], desperatio [desespero], impoenitentia [impenitência] (HEIDEGGER, 2002, p. $108)^{12}$

Isso fica mais claro com as observações de Heidegger (2002) acerca das palestras de Lutero sobre o Gênesis, em 1544. Primeiro, a diferença de opinião vinda da expressão iustitia originalis. Para os escolásticos, a retidão original não é uma parte natural do homem, mas apenas um adorno adicionado ao homem como um dom. Lutero, porém, afirma que a retidão era verdadeiramente parte da natureza humana, e por isso era a natureza de Adão amar a Deus, acreditar em Deus, conhecer a Deus.

Segundo, a Queda através do pecado. Lutero afirma que na passagem da Queda, Gênesis, capítulo 3, encontra-se o que era a maior e mais grave de todas as tentações, $\mathrm{o}$ ataque da serpente diretamente à boa vontade de Deus e a sua ousadia em provar que a vontade de Deus, voltada ao homem, não era boa. Isso é um ataque contra a verdadeira imagem de Deus. A tentação de Adão e Eva foi um movimento contra Deus e a sua Palavra, pois ambos ouviram uma palavra que não era a Palavra de Deus e envolveram-se em uma disputa [disputatio] que os levou a perder o seu ser original diante de Deus, Heidegger (2002).

Terceiro, o movimento do pecado. O homem vai da fé para a incredulidade, e a desobediência a Deus passa a ser algo insuportável. A fuga do homem perante Deus mostra que seu intelecto foi corrompido. A fuga de Adão é porque ele não vê que o pecado em si mesmo significa a atual fuga de Deus. O real significado do pecado é: o homem é quem foge de Deus, e fugindo por tal caminho que ele constantemente deseja distanciar-se mais, mantendo-se em uma eterna fuga. E, ao fugir, Adão justifica-se de seu pecado com mentiras, amontoando pecado sobre pecado. Assim, o pecado, pela sua própria gravitação, sempre atrai com isso outros pecados e leva-o a uma

\footnotetext{
${ }^{12}$ Tradução nossa: The being of man as such is itself sin. Sin is nothing other than the anthitesis to Faith, where faith means: standing (being placed) before God. Thus sin is not na affixing of moral attributes to man but rather his real core. In Luther, sin is a concept of existence, something that is emphasis on affectus already points to. Besides this fundamental definition of man, Luther turns his attention to the movement that sin as a mode of the being of man bears in itself: One sin begets another and drags man down ever deeper. The real sin is incredulitas, i.e., unbelief, aversio dei [turn away from God]. What is included in it, insofar as man is in this being-turned-away from God placed into the world, is a pavor [fear]. And with this furter sucession: fuga [flight], odium [hatred], desperatio [despair], impoenitentia [impenitence].
} 
eterna ruína. Essa fuga leva Adão a tentar esquivar-se de sua responsabilidade por meio de justificativas que culminam por transferir sua culpa para Deus. Os pecadores não podem fazer outra coisa senão acusar Deus e escusaremse, pois isso é o real desespero e isso vai ainda mais além: em sua justificativa, Eva mira sua acusação contra Deus como o Criador da serpente e, assim, caracteriza$\mathrm{O}$ como originador do pecado, $\mathrm{o}$ que se mostra como um pecado além de algo humano, um pecado claramente demoníaco; incredulidade transforma-se em blasfêmia, desobediência transforma-se em desacato ao Criador. Estas coisas são o último degrau do pecado, Heidegger (2002).

Em quarto lugar, Heidegger (2002) observa que a situação do homem que se distancia de Deus é uma relação que apresenta Deus, de certa maneira, visto pelas costas, no sentido de que Deus é rejeitado como um auctor peccati e o homem nega que Deus seja Deus. O que também necessita ser levado em conta é como o ser de Deus sempre está preocupado com o homem e como a sua palavra apresenta a fundamental relação do Criador com o homem, que é o ouvinte.

Em quinto lugar, Heidegger (2002) afirma evidenciar-se nestas observações como o pensa- mento de Lutero, em relação ao pecado, é totalmente diferente vis$\grave{a}$-vis do Escolasticismo e como ele considera o pensamento escolástico como uma antítese da fé. Em termos teológicos, isso significa que somente é possível o entendimento do que é a fé quando se entende o que seja o pecado, e, ao mesmo tempo, só é possível entender o pecado quando se tem um entendimento do ser do homem em si mesmo. A Teologia Protestante Contemporânea, por sua vez, geralmente não faz uma exibição sobre o esboço do entendimento do pecado e da relação de Deus e do homem aqui envolvidos. Quando isto é novamente explanado, nos movimentos teológicos mais recentes, procura-se mitigar e até dar-se combate a tais perspectivas, devido ao medo de que esse entendimento eleve-se a algo que possa subverter os princípios do protestantismo.

E em último lugar, Heidegger apresenta as observações sobre o Catolicismo e o protestantismo no periódico de Kierkegaard de 1852 (II, p. 284ss):

Protestantismo é somente um corretivo do Catolicismo e não pode pairar sozinho como uma normativa, apenas como Lutero é Lutero somente a partir das bases espiritu- 
ais do Catolicismo. Se o Catolicismo degenera, então "a santidade superficial" surge - se o Protestantismo degenera, então "a espiritualidade mundana" surge. Neste processo, o que deve ser incluído no Protestantismo é um refinamento que não pode se desenvolver no Catolicismo. Por último, quando um representante deste princípio degenerar para dentro do mundanismo, então ele traz sobre si mesmo o odium [desgraça] do mundanismo - quando um representante do Protestantismo degenera para dentro do mundanismo, então ele é louvado por sua piedade e franqueza. E neste caso, por causa do Catolicismo existe a pressuposição universal "de que nós seres humanos somos realmente desonestos [scoundrels]"; "o princípio do Protestantismo tem uma especial pressuposi- ção: um ser humano que está aqui em uma ansiedade mortal - em temor e tremor e em grande julgamento espiritual" (Søren Kierkegaard's Journal and Papers, vol. 3, pp.669672; Apud. HEIDEGGER, 2002, p.110)

\section{5 - Considerações finais}

Como foi apresentado nesse artigo, Heidegger migra de um catolicismo antimodernista para um protestantismo livre, deixando de lado o pensamento escolástico e tendo o pensamento protestante (especialmente Lutero) como importante fonte para o desenvolvimento de seu trabalho filosófico. $\mathrm{O}$ jovem Heidegger, por meio de Lutero, observa Agostinho e formula o que ele chama de Vida Cristã Originária, que é uma relação de amor e vida com o Deus vivo e pessoal, através da pessoa de Jesus Cristo, que se esvaziou a si mesmo (Fp 2,6-11), um Deus, portanto, que não se confunde com o Deus metafísico, isto

\footnotetext{
${ }^{13}$ Tradução Nossa: Protestantism is only a corrective to Catholicism and cannot stand alone as normative, just as Luther is Luther only on the spiritual basis of Catholicism. If Catholicism degenerates, then "surface sanctity" arises-if Protestantism degenerates, then "spiritless worldliness" arises. In the process, what would appear in Protestantism is a refinement that cannot develop in Catholicism. For in the latter, when a representative of its principle degenerates into worldliness, then he brings upon himself the odium [disgrace] of worldliness-when a representative of Protestantism degenerates into worldliness, then he is praised for his godliness and frankness. And this is the case, because in Catholicism the universal presupposition exists "that we human beings are really scoundrels"; "the principle of Protestantism has a special presupposition: a human being who sits there in mortal anxiety-in fear and trembling and great spiritual trial."
} 
é, o cristão, ao aproximar-se de Deus, deve, como Cristo, esvaziarse de si mesmo e reconhecer sua temporalidade, sua fragilidade e a importância da obediência a Deus no serviço (dom e tarefa).

Nessa Vida Cristã Originária, está presente a questão do pecado, e Heidegger observa atentamente como Lutero lidou com esse problema. Heidegger conclui que Lutero, diferentemente do pensamento escolástico, mostra que o pecado obliterou a natureza humana, pois, com a Queda, o homem perdeu o seu ser original e passou a considerar Deus como insuportável, desejando sempre estar mais e mais distante do Criador, negando a sua divindade: "Deus não é Deus". E mesmo apesar de tomar partido da visão de Lutero acerca do problema, Heidegger não deixa de defender que o Protestantismo é apenas um corretivo do Catolicismo e, ao mesmo tempo, um refinamento que não pode ocorrer no Catolicismo. Isto é, as questões que o pensamento Católico deixa obscuras são mais bem esclarecidas - como, v.g., as questões do pecado e da Queda, apresentadas neste artigo - no pensamento Protestante, principalmente no primeiro pensamento de Lutero. Não obstante, é preciso salientar, nem tudo no Catolicismo é deixado de lado por Heidegger, como, v.g., a postura piedosa de seu pai e do Padre Sancta Clara.

\section{Referências}

BUREN, John Van. "Martin Heidegger, Martin Luther". In: KISIEL, Theodore; BUREN, John van (Ed.). Reading Heidegger from the start: Essays in His Earliest Thought. Albany: State University of New York Press, 1994, pp. 159-174.

CAPELLE, Philippe. Philosophie E Théologie dans la pensée de Martin Heidegger. Paris: Cerfe, 2012.

CAPUTO, John. "Heidegger e a Teologia". In: GUIGNON, Charles B. Poliedro Heidegger. Tradução: João Carlos Silva. Lisboa: Instituto Piaget, 2010.

DRAWIN, Carlos Roberto. "Belo Horizonte. Ontologia e fenomenologia da vida religiosa no pensamento do jovem Heidegger". In: Anais do II Congresso Brasileiro de Filosofia da Religião. Belo Horizonte: PUC-Minas, 2007. p. 1-11. 
FABRIS, Adriano. "Martin Heidegger: O "ateísmo de princípio" da filosofia, a proveniência da fé em "Cristo, o Deus crucificado", e a permanência de instâncias teológicas na espera do "último deus". In: ZUCAL, Silvano (org.) Cristo na Filosofia Contemporânea Vol. II. São Paulo: Paulus, 2006, pp. 501-526.

FRANZ, Helmut. "Das Denken Heideggers und die Theologie". In: POGELLER, Otto (Org.). Heidegger: Perspektiven zur Deutung seines Werks. Koln: Kiepenheuer e Witsch, 1970.

GADAMER, Hans-Georg. Hegel - Husserl - Heidegger. Tradução: Marco Antônio Casanova. Petrópolis: Vozes, 2012.

HEIDEGGER, Martin \& BULTMANN, Rudolf. Martin Heidegger/ Rudolf Bultmann-Correspondência (1925-1975). GROMANN, Andreas; LANDMESSER, Christof (Editores). Tradução de Raúl Gabás. Barcelona: Herder Editorial, 2012.

HEIDEGGER, Martin. "The problem of sin in Luther". In: Martin Heidegger: Supplements - From the Earliest Essays to Being and Time Beyond. BUREN, John Van (trad.). New York: State University Of New York Press, 2002, pp. 105-110.

HEIDEGGER, Martin. Fenomelogia da Vida Religiosa. Tradução: Enio Paulo Giachini, Jairo Ferradin e Renato Kirchner. Petrópolis e Bragança Paulista: Vozes e Editora Universitária São Francisco, 2010. HEIDEGGER, Martin. Ontologia: Hermenêutica da Facticidade. Tradução: Renato Kirchner. Petrópolis: Vozes, 2012.

HEIDEGGER, Martin. Que é isto - A filosofia? Identidade e Diferença. Tradução de Ernildo Stein. São Paulo/Petrópolis: Vozes/Duas Cidades. 2006.

HEIDEGGER, Martin. Ser e Tempo. Bilíngue Alemão-Português. Tradução: Fausto Castilho. Petrópolis/Campinas: Vozes/Unicamp. 2012.

LEHMANN, Karl. "Christliche Geschichtserfahrung und ontologische Frage beim jungen Heidegger". In: POGGELER, Otto (Org.). Heidegger: Perspektiven zur Deutung seines Werks. Koln: Kiepenheuer e Witsch, 1970.

LUTERO, Martinho. Obras Selecionadas, Vol. I: Os Primórdios. Escritos de 1517 a 1519. Tradução: Annemarie Höhn; Ilson Kayser; Luís M. Sander; Martinho L. Hasse e Walter O. Schlupp. São Leopoldo e Porto Alegre: Sinodal e Concórdia Editora LTDA, 1987.

MACDOWELL, João A. "Martin Heidegger e o pensamento oriental: confrontos". In: Heidegger e o pensamento oriental. NETO, A.F. 
\& GIACOIA, O. (org.). Uberlândia: EDUFU, 2012, pp. 125-147.

OTT, Hugo. Martin Heidegger - En caminho hacia su biografia. Tradução de Helena Cortés Gabaudan. Madrid: Alianza Editorial. 1993.

PÖGGELER, Otto. "Martin Heidegger". In: FLEISCHER, Margot (Org.). Filósofos do século XX. São Leopoldo: Ed. Unisinos, 2000, pp. 154177.

SOLARI, Enzo. "Aproximación al problema de Dios en el pensamiento de Heidegger". In: II CONGRESO INTERNACIONAL DE FILOSOFIA XAVIER ZUBIRI. UCA, San Salvador, 2005, pp. 1-100.

WOLFE, Judith. Heidegger and Theology. London: Bloomsbury Academic, 2014.

Recebido: $20 / 01 / 2019$

Aprovado: 15/04/2019

Publicado: 13/05/2019 